J. Lake Sci.(湖泊科学), 2008, 20(1): 27-32

http://www.jlakes.org. E-mail: jlakes@niglas.ac.cn

(C)2008 by Journal of Lake Sciences

\title{
滇池福保湾沉积物磷的形态及其与间隙水磷的关系*
}

\author{
李 宝 ${ }^{1,2}$, 范成新 ${ }^{1}$, 丁士明 ${ }^{1}$, 张 路 ${ }^{1}$, 钟继承 ${ }^{1,2}$, 尹洪斌 ${ }^{1,2}$, 赵 斌 ${ }^{3}$ \\ (1: 中国科学院南京地理与湖泊研究所湖泊与环境国家重点实验室, 南京 210008) \\ (2: 中国科学院研究生院, 北京 100049) \\ (3: 西安建筑科技大学, 西安 710055)
}

摘 要: 研究了滇池福保湾沉积物中磷的地球化学形态及间隙水中 $\mathrm{PO}_{4}{ }^{3-}-\mathrm{P}$ 含量的垂向分布特征. 福保湾沉积物磷形态空间 差异大, 河口区 TP 高达 $(5630.59 \pm 424.25) \mathrm{mg} / \mathrm{kg}$, 东西沿岸区 TP 只有 $200-300 \mathrm{mg} / \mathrm{kg}$, 无机磷(I-P)是 TP 的主要部分, 占 TP 的 $55 \%-74 \%$, 铁/铝结合态磷(Fe/Al-P)是 I-P 的主要组成部分, 约占 I-P 的 $90 \%$, 不稳定性磷(L-P)含量很低, 只占 TP 含量的 $0.5 \%$. 福 保湾沉积物具有极高的 Fe/Al-P 含量, 说明湾内具有很高的内源磷负荷, 这与福保湾水体严重富营养化和藻类暴发关系密切. 湖湾沉积磷的垂向分布规律较复杂, 但基本上是随深度增加而减小, 说明福保湾周边区域近几年人类活动作用加强, 福保湾 污染有加重的趋势. 在湾内不同区域应用 Peeper(渗吸膜式)技术, 获得了间隙水中 $\mathrm{PO}_{4}{ }^{3-}-\mathrm{P}$ 的垂向分布特征, $\mathrm{PO}_{4}{ }^{3-}-\mathrm{P}$ 浓度自上 覆水向下层间隙水呈先升后降, 反映它们有自间隙水向上覆水扩散的趋势. 福保湾间隙水 $\mathrm{PO}_{4}{ }^{3-}-\mathrm{P}$ 浓度同沉积物 L-P 含量具有 显著正相关性 $(\alpha=0.05)$, 但 Fe/Al-P、Ca-P、org-P 和 TP 含量未发现有明显的相关关系.

关键词: 沉积物; 磷; 形态分布; Peeper; 间隙水; 滇池

\section{Phosphorus species in sediments and their relationships with soluble phosphorus concentrations in interstitial waters of Fubao Bay in Lake Dianchi}

\author{
LI Bao ${ }^{1,2}$, FAN Chengxin ${ }^{1}$, DING Shiming ${ }^{1}$, ZHANG Lu ${ }^{1}$, ZHONG Jicheng ${ }^{1,2}$, YIN Hongbin ${ }^{1,2} \&$ ZHAO Bin ${ }^{3}$ \\ (1: State Key Laboratory of Lake Science and Environment, Nanjing Institute of Geography and Limnology, CAS, Nanjing 210008, P. R. China) \\ (2: Graduate School of Chinese Academy of Sciences, Beijing 100049, P. R. China) \\ (3: Xi'an University of Architecture and Technology, Xi'an 710055, P. R. China)
}

\begin{abstract}
This paper presents investigations on geochemical species of phosphorus in sediments and vertical distributions of $\mathrm{PO}_{4}{ }^{3-}-\mathrm{P}$ in interstitial waters of Fubao Bay in Lake Dianchi. The sediments of Fubao Bay had high TP contents, with the maximum value of $(5630.59 \pm 424.25) \mathrm{mg} / \mathrm{kg}$. I-P(inorganic phosphorus) was the major part of TP, which was about $55 \%-74 \%$ of TP. Fe/Al-P (P bound to $\mathrm{Al}, \mathrm{Fe}$ and $\mathrm{Mn}$ oxides and hydroxides) was the major part of I-P, which was about $90 \%$ of I-P. The contents of L-P(labile phosphorus) were very low, which was about $0.5 \%$ of TP. The Fe/Al-P contents in sediments were very high, which were highly correlated with high eutrophication phenomenon and algae blooming events in Fubao Bay, implying a strong diffusion trend for sediment phosphorus in Fubao Bay. Vertical distributions of sediment phosphorus species were complicated, exhibiting a little disorder in both increased and decreased trends with the depth. This feature was related to the ecosystem conditions, pollutant discharge and sediment dynamic conditions in Fubao Bay. Peeper technique (in situ dialysis membrane samplers) was used to sample interstitial waters in sediments, and vertical distributions of $\mathrm{PO}_{4}{ }^{3-}-\mathrm{P}$ were achieved in the waters. The results showed that concentrations of $\mathrm{PO}_{4}{ }^{3-}-\mathrm{P}$ in interstitial waters had general increases followed by decreases with the depth, reflecting a possible diffusion trend for $\mathrm{PO}_{4}{ }^{3-}-\mathrm{P}$ from interstitial waters to overlying waters. Regression analyses showed that concentrations of $\mathrm{PO}_{4}{ }^{3-}-\mathrm{P}$ in the interstitial waters were positively correlated with L-P contents. Keywords: Sediment; phosphorus species distribution; Peeper; interstitial water; Lake Dianchi
\end{abstract}

\footnotetext{
* 国家高技术研究发展计划(863)项目(2005AA601010050201)、国家自然科学基金项目(20577053,40601087)和中国科学院 知识创新工程项目(KZCX3-SW-348)联合资助. 2007-04-22 收稿; 2007-09-12 收修改稿. 李宝, 男, 1980 年生, 博士研究生; E-mail: bli@niglas.ac.cn.
} 
福保湾位于滇池东北岸, 是由大清河和海河冲击扇包围形成的湖湾, 湖岸线长约 $3.16 \mathrm{~km}$, 面积约 $1 \mathrm{~km}^{2}$ (图1). 福保湾底泥由于长期接纳来自大清河、海河及湖湾周边地区的污染物, 受到了严重污染. 目 前, 福保湾面临水体严重富营养化、水生植被消失、蓝藻水华堆积及周边产业结构不合理等诸多问题.

磷是湖泊蓝藻水华暴发常见的限制性营养盐, 研究湖泊磷的生物地球化学循环行为对揭示湖泊富营 养化发生机制、治理蓝藻水华具有重要意义 ${ }^{[1]}$. 沉积物中能参与界面交换及生物可利用的磷含量取决于 沉积物中磷的形态，沉积磷在一定条件下可能是湖泊重要的营养物来源 ${ }^{[2]}$, 因此对沉积物中磷形态同间 隙水正磷酸盐的关系研究显的尤为重要. 沉积物中的磷形态大体可分为弱结合态 (L-P)、铁/铝结合态 $(\mathrm{Fe} / \mathrm{Al}-\mathrm{P})$ 、钻结合态 $(\mathrm{Ca}-\mathrm{P})$ 和有机结合态 $(\mathrm{Org}-\mathrm{P})$ 等 $^{[3]}$. 近年来, 对海洋、河口和湖泊沉积磷形态已有大量 研究 ${ }^{[4-10]}$, 但主要针对沉积物各磷形态和生物可利用磷的时空分布来开展, 而对沉积物磷形态同间隙水 磷营养盐关系的研究涉及较少. 本文利用SMT法和Peeper法分别获取了滇池福保湾不同区域沉积物磷形 态和底泥间隙水磷营养盐含量的垂向分布特征，并考察了它们之间的相互关系，探讨间隙水正磷酸盐的 来源, 为客观评价沉积物不同磷形态的潜在释放能力及其对湖泊富营养化水平贡献提供依据.

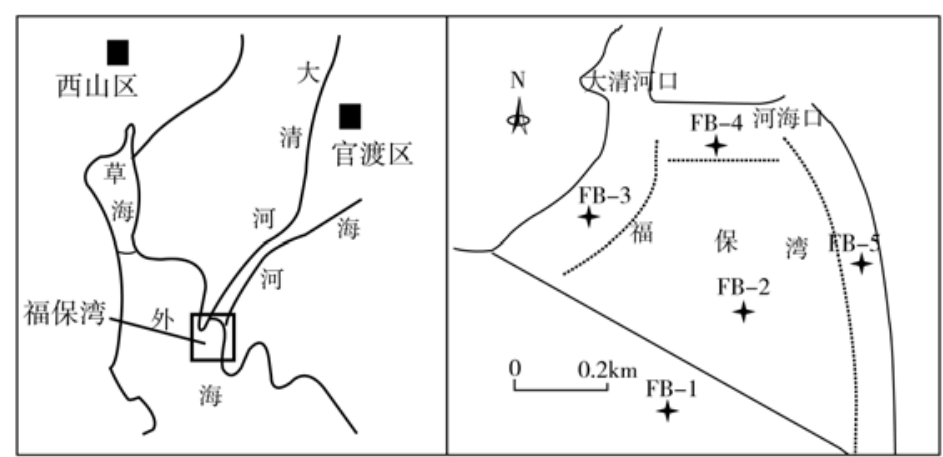

图 1 滇池福保湾采样点分布

FB-1, 湾外对照区 $\left(102^{\circ} 41^{\prime} 06.4^{\prime \prime} \mathrm{E}, 24^{\circ} 55^{\prime} 27.9^{\prime \prime} \mathrm{N}\right)$; FB-2, 湾心区 $\left(102^{\circ} 41^{\prime} 07.4^{\prime \prime} \mathrm{E}, 24^{\circ} 55^{\prime} 50.8^{\prime \prime} \mathrm{N}\right)$;

FB-3，西部沿岸区 $\left(102^{\circ} 40^{\prime} 59.4^{\prime \prime} \mathrm{E}, 24^{\circ} 55^{\prime} 53.1^{\prime \prime} \mathrm{N}\right)$; FB-4，河口区 $\left(102^{\circ} 41^{\prime} 10.1^{\prime \prime} \mathrm{E}, 24^{\circ} 56^{\prime} 03.7^{\prime \prime} \mathrm{N}\right)$;

FB-5, 东部沿岸 $\left(102^{\circ} 41^{\prime} 24.3^{\prime \prime} \mathrm{E}, 24^{\circ} 55^{\prime} 41.6^{\prime \prime} \mathrm{N}\right)$

Fig.1 Sampling locations of Fubao Bay in Lake Dianchi

\section{1 材料与方法}

\subsection{Peeper 结构简介}

Peeper 主体是由一系列小室组成, 小室两侧覆盖一层渗析膜, 室内预先封装去离子水, 利用渗析膜过滤 的特性，使膜两侧水体(如去离子水和间隙水)中一些可溶离子和分子交换达到平衡. 具体结构示意图见[11].

\section{2 样品采集与分析}

1.2.1 采样点的选择 福保湾东西两岸常年受风浪冲刷, 湖底底泥为坚硬而贫痊的沙质沉积物; 湾心及 河口常年接纳大清河、海河排放的城市污水及湖湾周边地区的污染物, 底泥发黑发臭, 污染严重. 为了较 好的了解整个福保湾的沉积物情况, 将福保湾划分为湾外对照区(FB-1)、湾心区(FB-2)、西部沿岸区 (FB-3)、河口区(FB-4)和东部沿岸区(FB-5)5个区域开展研究(图1).

1.2 .2 沉积物的采集 2006 年11月9日在样点处用装有 $\phi 85 \mathrm{~mm} \times 600 \mathrm{~mm}$ 有机玻璃管的柱状采泥器采集泥 样，每点采集3根平行样，返回实验室进行柱样分层. 分层采用上顶法，即用顶杆将底泥从柱样底部向上 小心顶出, 溢除上覆水后, 用切板切除. 柱样按 $2 \mathrm{~cm}$ 一层分样, 泥柱长度为 $10 \mathrm{~cm}$, 共 5 层, 选择了 $0-2 \mathrm{~cm}$, 4-6cm, 8-10 cm三层进行磷形态分析. 分层泥样放置在阴凉处, 于室温下自然阴干, 除去植物和贝类等残 体, 研磨混匀, 过100目篮, 备用.

1.2.3 间隙水的采集与分析 用自制Peeper 投放器 ${ }^{[12]}$ 向水下垂直投放Peeper 并插人底泥至预定深度. 自 Peeper 投放时间(2006年10月9日)计起，平衡30d，从泥中拔出Peeper，即刻用低压水枪冲洗其单面所附泥 


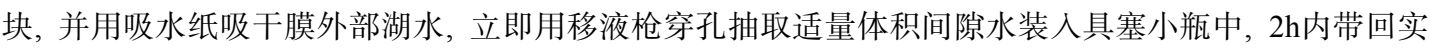
验室, 进行 $\mathrm{PO}_{4}{ }^{3-}-\mathrm{P}$ 的分析 ${ }^{[13]}$.

1.2 .4 沉积物含水率分析 采用朱广伟等 ${ }^{[14]}$ 的方法. 将湿沉积物填满金属小环 $(h=0.9 \mathrm{~cm}, \phi=1.75 \mathrm{~cm})$, 在 $105^{\circ} \mathrm{C}$ 下烘 $4 \mathrm{~h}$, 含水率为沉积物烘干前后质量差值与原有湿沉积物质量的比值.

1.2.5 磷形态的提取 磷形态分析采用SMT法 ${ }^{[15-17]}$, 磷形态分为铁铝结合态磷 $(\mathrm{Fe} / \mathrm{Al}-\mathrm{P})$ 、钙磷 $(\mathrm{Ca}-\mathrm{P})$ 、无 机磷(I-P)、有机磷( org-P)和总磷 $(\mathrm{TP})$. 另外, 采用 $1 \mathrm{~mol} / \mathrm{L} \mathrm{NH}_{4} \mathrm{Cl}$ 提取不稳定态磷 $(\mathrm{L}-\mathrm{P})^{[18]}$, 具体方法为: 称 取 $1.0 \mathrm{~g}$ 左右湿沉积物于离心管中, 加 $25 \mathrm{ml} 1 \mathrm{~mol} / \mathrm{L} \mathrm{NH} \mathrm{NCl}_{4}$ 液, 振荡 $0.5 \mathrm{~h}$, 离心, 钼蓝比色测定上清液中的磷 含量 ${ }^{[13]}$, 换算成单位质量干泥的含量.

\section{2 结果与讨论}

\section{1 磷形态含量分布}

从各磷形态组分绝对含量来看, 福保湾 5 个点位各磷形态组分差异较大, 尤其是 Fe/Al-P, 河口区 Fe/Al-P 含量是东西沿岸区的 20-30倍, 差异最小的是 org-P(表 2), 这与整个湖区有机颗粒物沉降较活性磷组分均 匀有关, 也与 org-P 参与磷循环相对 Fe/Al-P 等组分慢有关. FB-4 位于河口区，距离大清河和海河口最近, 污染最为严重，有机质含量极高，底泥发黑发臭，沉积物各磷形态含量也最高. FB-3 和 FB-5 位于福保湾 东西沿岸，常年受到风浪冲刷，底泥为贫痊的硬沙质泥层，沉积物磷含量在整个湖湾当中最低. 与张路 ${ }^{[4]}$ 在太湖和朱广伟 ${ }^{[19]}$ 在长江中下游湖泊所得到的数据相比, 福保湾沉积物 $\mathrm{Fe} / \mathrm{Al}-\mathrm{P}$ 组分要高的多, 是长江 中下游湖泊均值的 5 倍左右，这也与福保湾常年蓝藻水华堆积相吻合.

表 2 福保湾不同区域磷形态分布*

Tab.2 Phosphorus species in sediments of different locations in Fubao Bay

\begin{tabular}{ccccccc}
\hline 点位 & $\mathrm{L}-\mathrm{P}(\mathrm{mg} / \mathrm{kg})$ & $\mathrm{Fe} / \mathrm{Al}-\mathrm{P}(\mathrm{mg} / \mathrm{kg})$ & $\mathrm{Ca}-\mathrm{P}(\mathrm{mg} / \mathrm{kg})$ & $\mathrm{I}-\mathrm{P}(\mathrm{mg} / \mathrm{kg})$ & org-P $(\mathrm{mg} / \mathrm{kg})$ & $\mathrm{TP}(\mathrm{mg} / \mathrm{kg})$ \\
\hline FB-1 & $17.73 \pm 1.29$ & $842.94 \pm 56.43$ & $269.28 \pm 16.17$ & $1411.59 \pm 153.46$ & $1035.45 \pm 94.31$ & $2447.04 \pm 78.98$ \\
FB-2 & $13.93 \pm 1.64$ & $1941.20 \pm 249.61$ & $382.70 \pm 37.54$ & $2792.98 \pm 144.57$ & $1294.72 \pm 178.63$ & $4087.71 \pm 146.71$ \\
FB-3 & $1.03 \pm 0.33$ & $56.05 \pm 1.52$ & $13.95 \pm 0.81$ & $103.41 \pm 12.65$ & $88.41 \pm 5.92$ & $191.82 \pm 14.68$ \\
FB-4 & $9.93 \pm 2.62$ & $3094.54 \pm 193.49$ & $414.41 \pm 71.86$ & $4129.38 \pm 347.83$ & $1501.25 \pm 278.06$ & $5630.59 \pm 424.25$ \\
FB-5 & $1.33 \pm 0.52$ & $135.66 \pm 19.04$ & $8.65 \pm 0.94$ & $165.02 \pm 30.48$ & $135.75 \pm 20.35$ & $300.78 \pm 12.67$ \\
\hline
\end{tabular}

* 表中数据为表层 $10 \mathrm{~cm}$ 沉积物各磷形态含量的均值.

由各磷形态组分在总磷中的比例可以看出，沉积物 5 种磷形态(L-P、Fe/Al-P、Ca-P、I-P 和 org-P)平均 含量以 I-P 最高, 河口区高达 $(4129.38 \pm 347.83) \mathrm{mg} / \mathrm{kg}$, 无机磷(I-P)是 TP 的主要部分, 占 TP 的 $55 \%-74 \%$, $\mathrm{Fe} / \mathrm{Al}-\mathrm{P}$ 是 I-P 的主要组成部分, 约占 I-P 的 $90 \%$, L-P 含量很低, 只占 TP 含量的 $0.5 \%$ 左右(表 2). FB-1、 FB-2 和 FB-4 各磷形态含量的大小顺序是 Fe/Al-P $>$ org-P $>$ Ca-P $>$ L-P, 其中 Fe/Al-P 含量在 50\%左右, 这一 结果与其它湖泊不一致, 如太湖 ${ }^{[4]}$ 、红枫湖和百花湖 ${ }^{[20]}$ 都是 org-P 含量最高, Ca-P 次之, Fe-P 居中. Fe/Al-P 是具有释放潜力的一部分磷 ${ }^{[21]}$, 其含量基本可以反映出沉积磷的潜在释放量, 这也说明了滇池福保湾与 其它湖泊相比, 具有更大的内源磷负荷. 沉积物中 L-P 活性最强, 但含量很低, 不足以提供藻类生长所需 要的全部磷 ${ }^{[4]}, \mathrm{Fe} / \mathrm{Al}-\mathrm{P}$ 因而成为沉积物活性磷的最主要储存库.

\section{2 磷形态垂直分布规律}

福保湾沉积物磷形态含量在垂向上表现为波动, 基本是随深度增加而减小(图 2). FB-3 和 FB-5 磷形 态随深度增加而减少的趋势最为明显, 尤其是 FB-5, 表层磷形态含量是下层的 4 倍左右, 这是由于 FB-3 和 FB-5 位于东西沿岸区，沉积物为坚硬的沙质层，受其它外界条件影响较小的原因. FB-1、FB-2 和 FB-4 三个点各磷形态含量的垂向分布特征比较复杂, 既有随深度增加的, 也有随深度减小的, 这与三个点位 于对照区、湖湾区和河口区，常年受大清河和海河外源输人及风浪的影响，表层沉积物为发黑发臭的浮 泥，沉积物性质不够稳定等因素有一定关系.

L-P 在沉积垂向上随深度增加明显减小, FB-2 和 FB-4 表层 L-P 的含量为 $20 \mathrm{mg} / \mathrm{kg}$ 左右, $10 \mathrm{~cm}$ 层为 
$9 \mathrm{mg} / \mathrm{kg}$ 左右, 而 FB-1 表层 L-P 含量则高达 $30 \mathrm{mg} / \mathrm{kg}$, 这可能与 FB-2 和 FB-4 水比较浅, 风浪扰动较频繁 有关. 与张路等人 ${ }^{[4]}$ 在太湖得出的 L-P 含量不到 $4 \mathrm{mg} / \mathrm{kg}$ 相比, 福保湾 L-P 含量要比太湖高得多.

铁存在着氧化还原平衡，当三价铁被还原为二价铁时，结合的磷随着二价铁的溶出而被释放到间隙 水, 进而在浓度剃度的作用下进人上覆水体 ${ }^{[4]}$. Fe/Al-P 是福保湾沉积物中主要的活性磷组分, 图 2 中各样 点(除 FB-1)在垂直剖面上表现出下降的趋势, 这是由于随着深度的增加, 沉积物中的非晶矿物逐步有序 化, 铁的氧化物和氢氧化物的结合能力逐渐降低 ${ }^{[20]}$. 另外, 随深度增加, 沉积物还原能力大大增强, 促使 三价铁向二价铁转化和 Fe/Al-P 释放 ${ }^{[21]}$.

Ca-P 和 org-P 是沉积物中比较惰性的磷组分, 较难被生物利用, 对上覆水和间隙水的磷含量影响也比较 小. 在垂向分布趋势上基本是随深度增加而减小的, 这可能与各区域污染历史及水生植被变动状况等有关 ${ }^{[4]}$.

I-P 和 TP 在垂向上的变化规律基本是一致的, 除了 FB-4 外, 其它点位都是随深度的增加而降低, 表 层磷含量在沉积物中占很大比例, 这说明近几年福保湾磷污染有加重的趋势, 表层 I-P 含量多, 也与表层

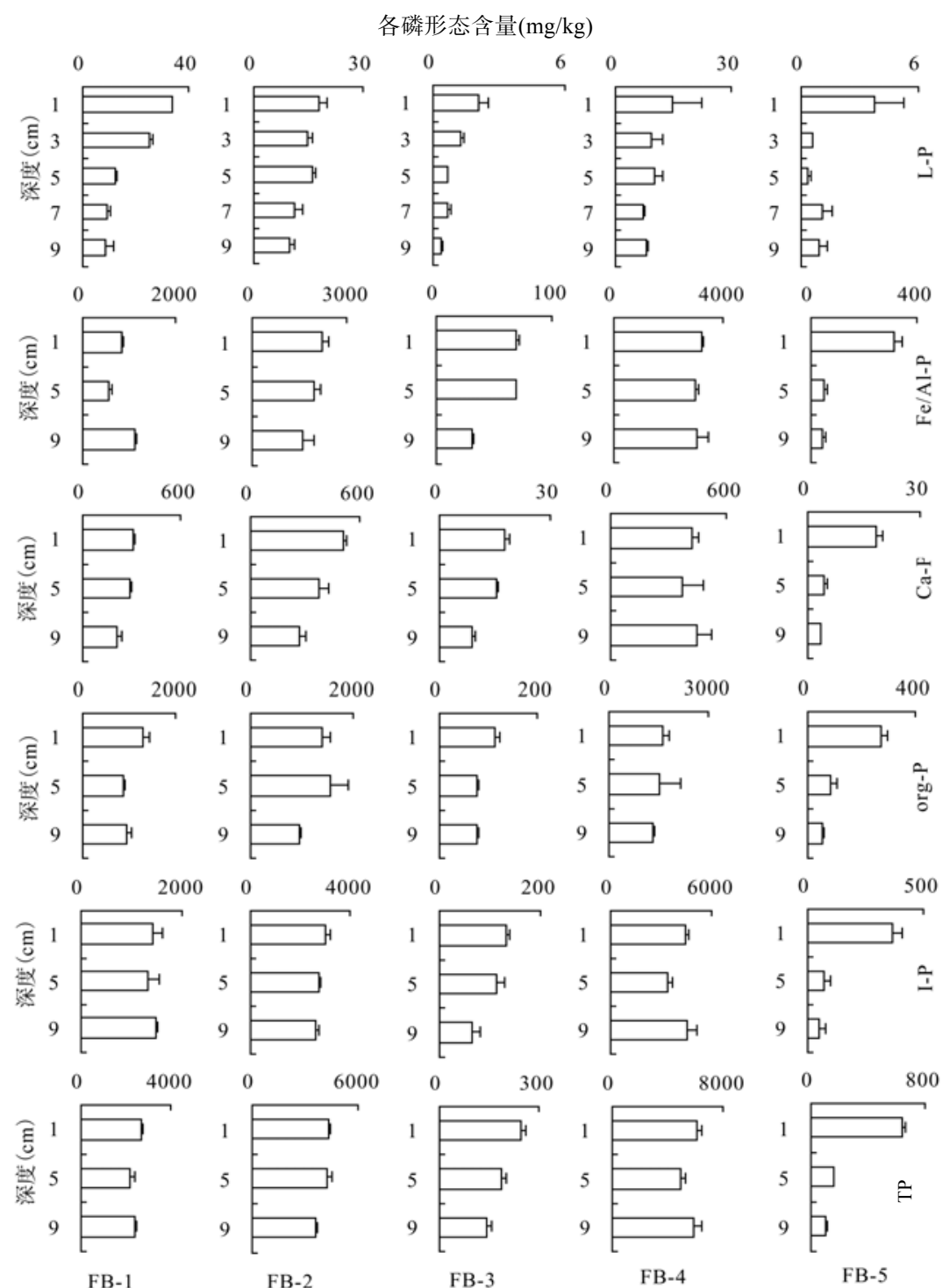

图 2 福保湾样点沉积磷形态垂直分布曲线

Fig.2 Vertical distribution of sediment phosphorus species of Fubao Bay 
生物活动旺盛有一定关系 ${ }^{[8]}$. FB-4 点 I-P 和 TP 是在 4-6 $\mathrm{cm}$ 处含量最低, 随深度增加磷含量有所上升, 这 与 FB-4 位于河口区, 受大清河和海河影响较大有一定关系(图 2).

沉积物磷形态特征受多方面因素的影响, 磷形态含量的垂向分布特征一般也比较复杂, 要想合理解 释各磷形态在垂向上的变化趋势, 还需要更多的工作来协同进行 ${ }^{[4]}$.

\section{3 间隙水磷营养盐分布特征}

图 3 为福保湾不同区域底泥间隙水 $\mathrm{PO}_{4}{ }^{3-}-\mathrm{P}$ 含量的垂直分布. 总体而言, 上覆水 $\mathrm{PO}_{4}{ }^{3-}-\mathrm{P}$ 含量较低, 维 持在 0.05-0.2mg/L 之间, 间隙水 $\mathrm{PO}_{4}{ }^{3-}-\mathrm{P}$ 含量在垂向上都有先升高后降低的趋势. 在表层 $10 \mathrm{~cm}$ 内, $\mathrm{PO}_{4}{ }^{3-}-\mathrm{P}$ 含量出现较大的跳跃式上升, $10 \mathrm{~cm}$ 以下，含量又出现较大的跳跃式下降， $\mathrm{PO}_{4}{ }^{3-}-\mathrm{P}$ 浓度在垂直方向的差异 表明了底泥有向上覆水释放的趋势. 比较 5 个点位间隙水 $\mathrm{PO}_{4}{ }^{3-}-\mathrm{P}$ 含量可以看出, FB-1 $>$ FB- $4>\mathrm{FB}-2>\mathrm{FB}-3>\mathrm{FB}-5$, FB-1 在 $5 \mathrm{~cm}$ 处含量达到 $2.4 \mathrm{mg} / \mathrm{L}$, 是 FB-2、FB-3 和 FB-4 的 2 倍多, 这与 FB-1 处水比较深, 受风频繁扰 动较小, 向上覆水释放较慢有关. FB-5 间隙水 $\mathrm{PO}_{4}{ }^{3-}-\mathrm{P}$ 含量最大处只有 $0.2 \mathrm{mg} / \mathrm{L}$, 这是因为 FB-5 位于东部 沿岸区，同西部沿岸(FB-3)相比，东部处于下风口，底泥受到风浪更强烈的冲刷，底质为坚硬的沙质层， 间隙水中很难保持较高的 $\mathrm{PO}_{4}{ }^{3-}-\mathrm{P}$ 含量.
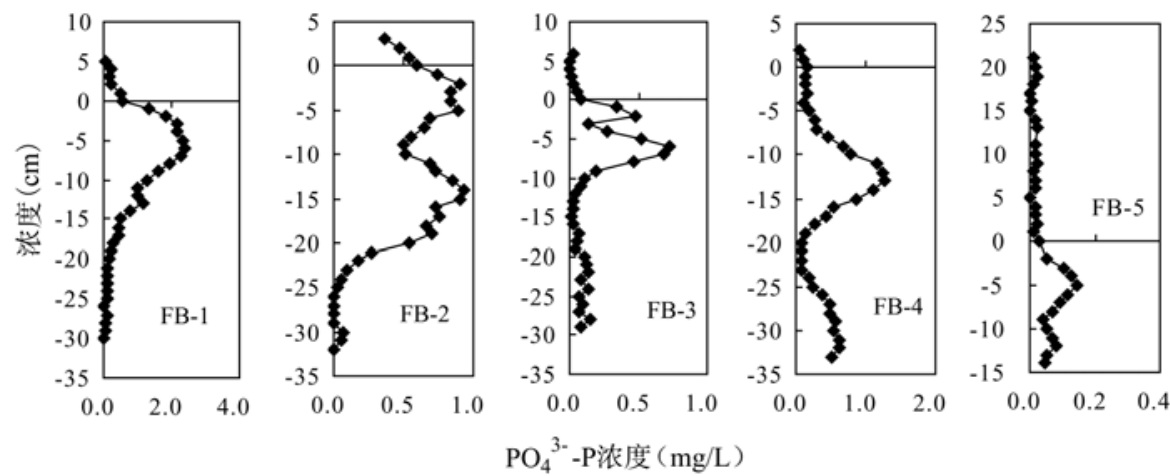

图 3 福保湾间隙水磷营养盐垂直变化

Fig. 3 Vertical changes of $\mathrm{PO}_{4}{ }^{3-}-\mathrm{P}$ in the interstitial water of Fubao Bay

表 3 福保湾间隙水中 $\mathrm{PO}_{4}{ }^{3-}-\mathrm{P}$ 浓度同沉积物各磷形态含量的对应关系

Tab.3 Relationships of $\mathrm{PO}_{4}{ }^{3-}-\mathrm{P}$ concentrations in interstitial waters with phosphorus contents of different phosphorus species in sediments of Fubao Bay

\begin{tabular}{llllllll}
\hline 因子 & L-P & Fe/Al-P & Ca-P & I-P & org-P & TP & PO $_{4}{ }^{3-}-\mathrm{P}$ \\
\hline L-P & 1.000 & & & & & \\
Fe/Al-P & 0.440 & 1.000 & & & & & \\
Ca-P & $0.702^{* *}$ & $0.893^{* *}$ & 1.000 & & & & \\
I-P & 0.482 & $0.986^{* *}$ & $0.919^{* *}$ & 1.000 & & & \\
org-P & $0.751^{* *}$ & $0.898^{* *}$ & $0.961^{* *}$ & $0.908^{* *}$ & 1.000 & & \\
$\mathrm{TP}^{* *}$ & $0.567^{*}$ & $0.980^{* *}$ & $0.949^{* *}$ & $0.993^{* *}$ & $0.951^{* *}$ & 1.000 & \\
$\mathrm{PO}_{4}{ }^{3-}-\mathrm{P}$ & $0.549^{*}$ & -0.004 & 0.370 & 0.087 & 0.331 & 0.158 & 1.000 \\
\hline
\end{tabular}

*显著性水平 $\alpha=0.05 ; * *$ 显著性水平 $\alpha=0.01, n=15$.

\section{4 沉积物磷形态同间隙水 $\mathrm{PO}_{4}{ }^{3-}-\mathrm{P}$ 的相关性分析}

将福保湾沉积物各点各层样品磷形态含量同底泥间隙水 $\mathrm{PO}_{4}{ }^{3-}-\mathrm{P}$ 浓度 $\left(\mathrm{PO}_{4}{ }^{3-}-\mathrm{P}\right.$ 浓度为 $0-2 \mathrm{~cm} 、 4-6 \mathrm{~cm}$ 和 
8-10cm的均值)进行相关性分析(表3). 福保湾沉积物各磷形态之间(L-P除外)都有显著的相关性 $(\alpha=0.01)$, 同 郭建宁 ${ }^{[8]}$ 等在福保湾得出的结果相一致. 沉积物间隙水 $\mathrm{PO}_{4}{ }^{3-}-\mathrm{P}$ 浓度除了与L-P含量显著正相关外 $(\alpha=0.05)$, 与 其它磷形态几乎无对应关系，表明间隙水中 $\mathrm{PO}_{4}{ }^{3-}-\mathrm{P}$ 的浓度直接决定于L-P. 张路等人 ${ }^{[4]}$ 在太湖发现沉积物 $\mathrm{Fe} / \mathrm{Al}-\mathrm{P}$ 含量与水体磷酸盐具有好的相关性, 认为Fe/Al-P含量对太湖水体富营养化具有重要影响, 福保湾没有 发现这一相关性, 可能与福保湾是由大清河和海河冲击扇包围形成的湖湾有关系, 福保湾环境比太湖更加复 杂多变, 间隙水 $\mathrm{PO}_{4}{ }^{3-}-\mathrm{P}$ 的产生与去向受到更多条件的制约和影响, 比如底泥污染水平、沉积物理化性质、氧化 还原状况和水动力影响程度等. 福保湾沉积物中 org-P含量与间隙水磷酸盐的相关关系也不明显, 这说明org-P 虽对水体有机负荷影响较大，但并不直接影响间隙水体磷酸盐含量. 范成新等 ${ }^{[22]}$ 对太湖不同湖区间隙水 $\mathrm{PO}_{4}{ }^{3-}-\mathrm{P}$ 浓度同底泥T-P含量的相关性进行了研究，太湖各湖区几乎无对应关系，太湖底泥赋存总磷的多少对间 隙水 $\mathrm{PO}_{4}{ }^{3-}-\mathrm{P}$ 浓度大小并不起决定因素, 这与在福保湾沉积物中的研究结果趋于一致.

致 谢: 中国科学院水生所滇池野外站为本研究提供了所需场地和试验设备, 中国科学院水生生物研究 所王智硕士、涂新海硕士，华中师范大学张彦辉硕士、孙小磊硕士在采样和切样时给予帮助，在此表示 感谢!

\section{3 参考文献}

[1] 范成新, 王春霞主编. 长江中下游湖泊环境地球化学与富营养化. 北京: 科学出版社, 2006: 71 -74.

[2] Ruttenberg KC. Development of aseqential extraction method for different forms of phosphorus in marine sediments. Limnol \& Oceanogr, 1992, 37(7): 1460-1482.

[3] 黄清辉, 王东红, 王春霞等. 沉积物中磷形态与湖泊富营养化的关系. 中国环境科学, 2003, 23(6): 583-586.

[4] 张 路, 范成新, 池俏俏等. 太湖及其主要人湖河流沉积磷形态分布研究. 地球化学, 2004, 33(4): 423-432.

[5] 许金树, 李亮歌. 台湾海峡中、北部沉积物中磷的存在形态. 海洋与湖沼, 1990, 21(1): 62-69.

[6] 陈淑美，傅天佑，林建云．厦门西港表层沉积物磷的形态与分布．台湾海峡, 1991, 10(3): 235-239.

[7] Fu YQ, Zhou YY, Li JQ. Sequential fractionation of reactive phosphorus in the sediment of a shallow eutrophic lake-Donghu Lake, China. Journal of Environmental Sciences, 2000, 12(1): 57-62.

[8] 郭建宁, 卢少勇, 金相灿等. 滇池福保湾沉积物不同形态磷的垂向分布. 环境科学研究, 2007, 20(2): 78-83.

[9] 张 路, 范成新, 朱广伟等. 长江中下游湖泊沉积物生物可利用磷分布特征. 湖泊科学, 2006, 18(1): 36-42.

[10] 王 琦, 姜 霞, 金相灿等. 太湖不同营养水平沉积物磷形态与生物可利用磷的分布及相互关系. 湖泊科学, 2006, 18(2): 120-126.

[11] 张 路. 太湖水土界面过程与内源发生机制[学位论文]. 南京: 中国科学院南京地理与湖泊研究所, 2004: 19-20.

[12] 范成新. 孔隙水采样器水下投放装置. 中国专利: ZL02263161.5, 2003-05-28.

[13] 金相灿主编. 湖泊富营养化调查规范(第二版). 北京: 中国环境科学出版社, 1990: 164-187.

[14] 朱广伟. 水动力作用与浅水湖泊磷的内源负荷研究[博士后工作研究报告]. 南京: 中科院南京地理与湖泊所, 2003.

[15] Ruban V, López-Sánchez JF, Pardo P et al. Harmonized protocol and certified reference material for the determination of extractable contents of phosphorus in freshwater sediments-A synthesis of recent works. Fresenius J Anal Chem, 2001, 370: 224-228.

[16] Ruban V, Brigault S, Demare D et al. An investigation of the origin and mobility of phosphorus in freshwater sediments from Bort-Les-Orgues Reservoir, France. J Environ Monitor, 1999, 1(4): 403-407.

[17] 黄清辉, 王东红, 王春霞等. 太湖梅梁湾和五里湖沉积物磷形态的垂向变化. 中国环境科学, 2004, 24(2): 147-150.

[18] Pettersson K. Phosphorus characteristics of settling and suspended particles in Lake Erken. Science of the Total Environment, 2001, 266(1-3): 79-86

[19] 朱广伟, 秦伯强, 高 光等. 长江中下游浅水湖泊沉积物中磷的形态及其与水相磷的关系. 环境科学学报, 2004, 24(3): 381-388. [20] 王雨春, 万国江, 王仕禄等. 红枫湖、百花湖沉积物中磷的存在形态研究. 矿物学报, 2000, 20(3): 273-278.

[21] 朱广伟, 高 光, 秦伯强等. 浅水湖泊沉积物中磷的地球化学特征. 水科学进展, 2003, 14(6): 713-719.

[22] 范成新, 杨龙元, 张 路. 太湖底泥及其间隙水中氮磷垂直分布及相互关系分析. 湖泊科学, 2000, 12(4): 359-366. 